\title{
A SLIDE RULE FOR CLASS ROOM USE.
}

\author{
By Ernest W. Ponzer, \\ Leland Stanford Junior University.
}

That a world-wide movement in mathematical circles aiming at a greater efficiency in the teaching of mathematics has been gradually gaining momentum during the last ten years can hardly be denied. It may further be stated that many teachers of mathematics in secondary schools have caught this spirit of reform-and lived up to it--some time in advance of their colleagues in the colleges and universities. At present we have the spectacle of an international committee of university professors of mathematics at work on the problem in response to the demand for this greater efficiency. Undoubtedly, one of the causes of this demand for efficiency is found in the recent remarkable development of all branches of applied science, especially those of technology. The spirit of efficiency is prevalent there to a marked degree; in fact, of primary importance. Especially is this true in engineering practice in the United States. The teacher of mathematics, either in the secondary school or university, must get this spirit in order that he may use the short time a student is with him to the best advantage.

We have heard much of the Perry movement, laboratory methods, correlation, humanizing of mathematics, and other movements, all trying to solve the same problem and all helping to secure a greater efficiency. In this day we do not hesitate to use, in fact it is our duty to use, all those aids which will help round out any course in mathematics from arithmetic up. Teachers no longer hesitate to use graphical methods to illustrate many principles in algebra, nor refuse to employ analytical methods when these help fix the principles of geometry.

In this connection we wish to make the suggestion that there is no valid reason why the study, and especially the use of mathematical instruments, should be deferred to the latter years of a student's college course. The writer has used for several years in his work with freshman and sophomore students in the university several such home-made instruments, one of which, a slide rule of liberal size, has been fastened to the wall of the class room; and he has further insisted that every student be prepared, after a reasonable time, to check up his numerical work on the same. 

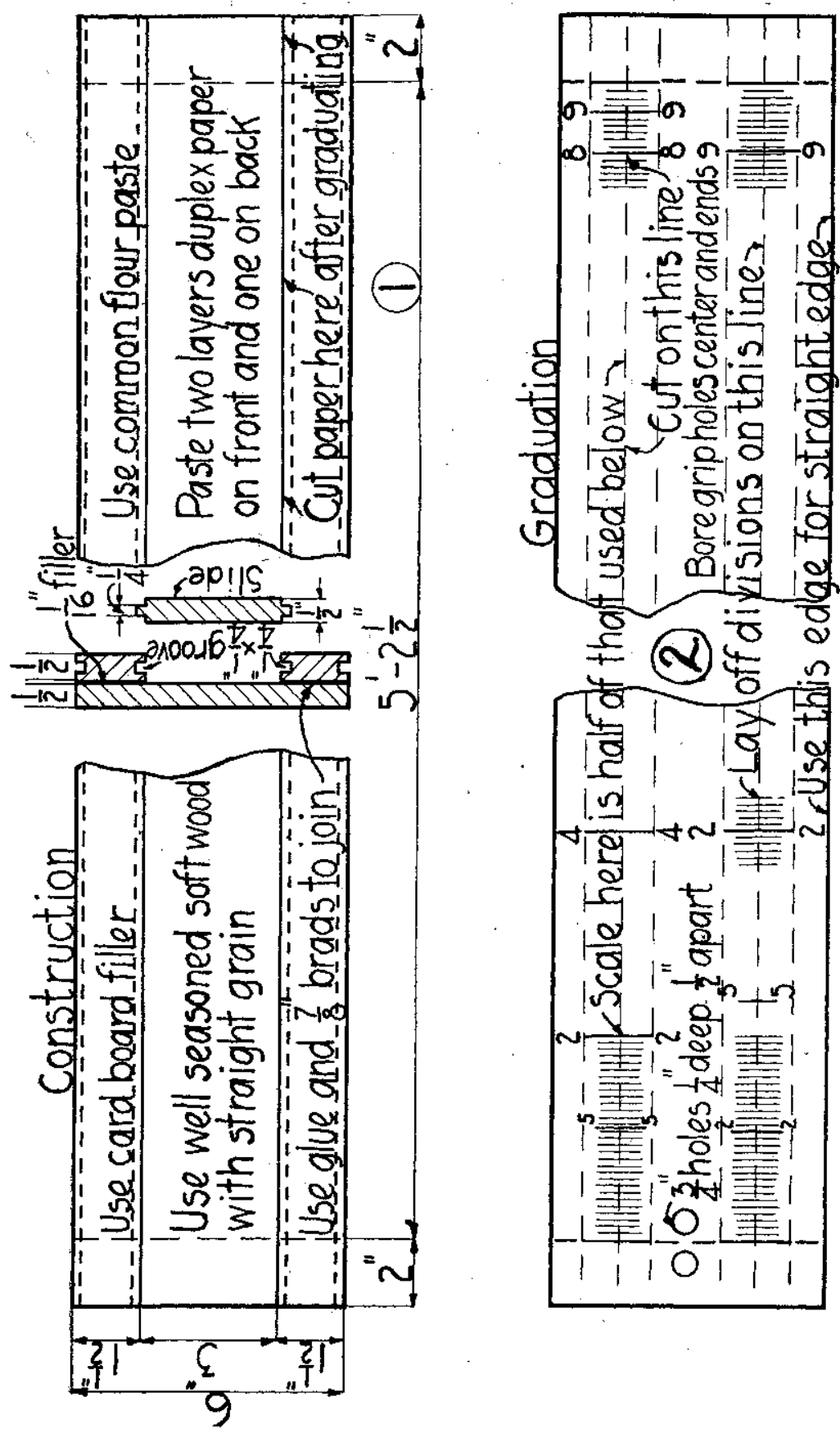
The theory of the slide rule is simple and well known; its application soon becomes more so, yet the knowledge of the principle and ability to use the same may be regarded as a secondary object, the main or fundamental idea in view being to check up results. Here is where we should learn our lesson from everyday life. To check up results implies that there should be a result to a problem, and further that the student's mathematical conscience should tell him when the result is correct. Any independent method which helps him develop this self-reliance is worth while, and the slide rule is preëminently such an aid.

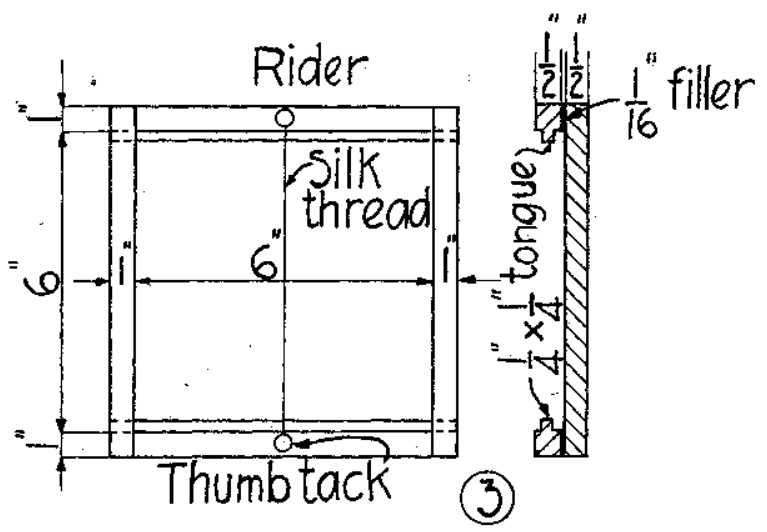

However, we wish to go a step further at this point and venture the suggestion that every teacher of secondary mathematics would find in it an inspiration for better work and suitable for use as soon as the student has studied the subject of exponents. We are not advising that every high school student should carry his slide rule, bought ready made, with him; rather should he be able to construct one, and that of any size which may appeal to him. Sufficient explanation is given in connection with the accompanying working drawings which will enable any student having done the rudiments of manual training to construct such a rule for class room use, or one on a smaller scale for desk use.

It will be noted that no provision is made for the direct reading of trigonometric functions, the idea being to stick to fundamentals and to obtain ease of operation, the rule being fastened to the wall with screws. It will be necessary to supplement its use with tables; but perhaps, from a pedagogical standpoint, this may be regarded as an advantage.

It may hardly be necessary to state here that the numbers on the rule are laid off according to their logarithms-exponents- 
and yet it may be in order to mention that 1,000 divisions each I/I6 inch in length were laid off on the face of the rule, as shown by the light lines in Fig. (2). Evidently, by referring to a table of logarithms, the figure 2 is placed opposite the $30 r$ 'st of these divisions from the left and similarly the figure 3 opposite the 477.I division. Various devices for estimating the tenths will suggest themselves, among others a piece of paper on which are measured ten equal divisions laid at an angle between two consecutive lines. The number of subdivisions between two numbers will depend on the numbers, and perhaps it would be best to have, say a Io inch rule for a pattern. On the upper scale 2 would be laid off opposite the 150.5 division and 3 opposite the division corresponding to the logarithm of 1.732 . If a rule is desired giving also cubes and cube roots directly it will be seen that the extra scale to be laid off should be simply $1 / 3$ that of the lower scale. Holes $3 / 4$ inch in diameter bored in pairs, with centers $I / 2$ inches apart, at either end and in the middle, will serve as grips for moving the slide. Figure (3) gives a working drawing of the rider, the cross hair of which can readily be adjusted by means of the thumb-tacks.

The rule, once installed, will be used frequently and be found eminently practical; yet should it serve no other purpose than just to stimulate the student's interest and help develop his mathematical sense it would be found well worth while.

\section{OFFICIAI DEMONSTRATIONS CONVINCING.}

Most of the leading mining men of this country have long believed that coal dust is in itself an agent of disastrous explosion, but until public demonstrations had been made at the government testing station at Pittsburg, many doubted that it possessed explosive power without the aid of fire damp. Its explosibility is now unquestioned and it is generally admitted that many so-called "windy shots" and "powder explosions" have been really dust explosions.

\section{IMITATION GEMS.}

The one quality of most of gems that cannot be duplicated successfully in their imitation is their hardness. Glass will yield to a file, while gems will not. The glass used in making imitation gems usually has a high percentage of lead in its composition. The lead makes it soft, but gives it a great brilliancy. The glass is commonly known as paste or strass. Uncolored, it affords a good imitation of the diamond, and it can be colored with metallic oxides to produce remarkably good imitations of other gems. 